\title{
EFFECT OF W COATING ON MICROENGINE PERFORMANCE
}

\author{
S. S. Mani, J. G. Fleming, J. A. Walraven, J. J. Sniegowski, M. P. de Boer , L. W. Irwin, D. M. Tanner, D. A. LaV \\ M. T. Dugger, J. Jakubczak, and W. M. Miller \\ Sandia National Laboratories \\ MS 1084, PO Box 5800; Albuquerque, NM 87185 \\ 505284 6606; fax: 505844 2991; e-mail: ssmani@sandia.gov
}

\begin{abstract}
Two major problems associated with Si-based MEMS (MicroElectroMechanical Systems) devices are stiction and wear. Surface modifications are needed to reduce both adhesion and friction in micromechanical structures to solve these problems. In this paper, we will present a CVD (Chemical Vapor Deposition) process that selectively coats MEMS devices with tungsten and significantly enhances device durability. Tungsten CVD is used in the integrated-circuit industry, which makes this approach manufacturable. This selective deposition process results in a very conformal coating and can potentially address both stiction and wear problems confronting MEMS processing. The selective deposition of tungsten is accomplished through the silicon reduction of $\mathrm{WF}_{6}$. The self-limiting nature of the process ensures consistent process control. The tungsten is deposited after the removal of the sacrificial oxides to minimize stress and process integration problems. The tungsten coating adheres well and is hard and conducting, which enhances performance for numerous devices. Furthermore, since the deposited tungsten infiltrates under adhered silicon parts and the volume of $\mathrm{W}$ deposited is less than the amount of $\mathrm{Si}$ consumed, it appears to be possible to release adhered parts that are contacted over small areas such as dimples. The wear resistance of tungsten coated parts has been shown to be significantly improved by microengine test structures.
\end{abstract}

\section{INTRODUCTION}

Surface micromachined devices are currently fabricated from polycrystalline silicon, which is used by the silicon microelectronics industry as a gate electrode and local interconnect [1]. Parts fabricated from polysilicon, a material originally developed for its electronic properties, have been demonstrated to be mechanically robust [2]. However, wear has been identified as a significant failure mechanism for devices with contacting and load bearing surfaces [35]. Figure 1 shows a complex five level polysilicon structures with contacting and moving parts fabricated at Sandia National Laboratories.

Some approaches to the problem of wear include the introduction of a low friction polymeric coating, for example by PECVD (Teflon) or introduction of self assembled monolayers, through wet chemical routes after the release process $[6,7]$. In these approaches the deposited layer itself is not hard but wear is diminished by the reduction in the coefficient of friction. The long-term behavior of these very thin layers of polymeric materials is unclear. A fundamentally different approach to the wear problem is to substitute the polysilicon with intrinsically hard materials such as diamond or silicon carbide. However, this runs counter to the great enabling strength of polysilicon surface micromachining, which is the leveraging of IC processing technology and tool sets. Thus, the big drawback to this approach involves process integration. Most devices with contacting layers consist of a minimum of three mechanical levels fabricated using a complicated combination of deposition, photolithographic, etch, and planarization processes. The introduction of completely new materials and processing technologies into these complex process flows may be difficult and require further development efforts. Therefore, development of better surface passivation and tribological coatings using standard IC processing tool sets is of great importance for the successful widespread introduction of MEMS sensors and actuators with contacting surfaces. In this paper we demonstrate that coating with selectively deposited, selflimiting, tungsten coating can dramatically improves the wear characteristics of microengines with much less process impact.

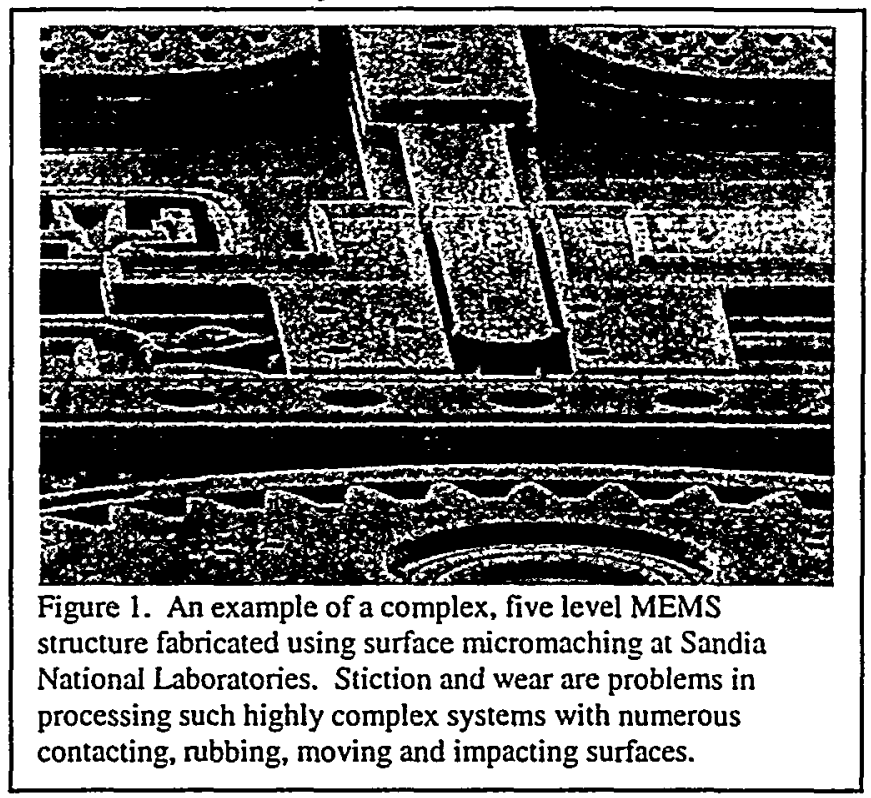

The selective deposition of tungsten through the silicon reduction of $W_{6}$ was studied in detail in the late 1980's but never gained acceptance by the IC industry [8-13] However, blanket tungsten CVD, using silane or hydrogen reduction is commonly used in the integrated-circuit industry. Fortunately, this same tool set can be applied to the selective silicon reduction process outlined here. The selective deposition of tungsten is accomplished through silicon reduction of $\mathrm{WF}_{6}$, which results in a self-limiting reaction $[11,12]$. The self-limiting nature of this deposition process ensures consistent process control and results in a very conformal coating. "The ability to selectively deposit $W$ after the removal of the sacrificial oxide and the low temperature of the deposition $\left(<450^{\circ} \mathrm{C}\right)$ eases process integration. Furthermore, since the deposited nungsten infiltrates under adhered silicon parts and the volume of $\mathrm{W}$ deposited is less than the amount of Si consumed, it appears to be possible to release adhered parts that are contacted over small areas such as dimples.

Tungsten has a number of attractive properties as a wear resistant coating. Endurance of the W coating is important, especially in applications where wear may occur due to rubbing or contacting surfaces. Unlike polymeric coatings, which only serve to reduce the coefficient of friction, $\mathrm{W}$ is hard. Also unlike the polymers, $\mathrm{W}$ is entirely compatible with the temperatures typically associated with packaging and is ultra high vacuum compatible. 


\section{DISCLAIMER}

This report was prepared as an account of work sponsored by an agency of the United States Government. Neither the United States Government nor any agency thereof, nor any of their employees, make any warranty, express or implied, or assumes any legal liability or responsibility for the accuracy, completeness, or usefulness of any information, apparatus, product, or process disclosed, or represents that its use would not infringe privately owned rights. Reference herein to any specific commercial product, process, or service by trade name, trademark, manufacturer, or otherwise does not necessarily constitute or imply its endorsement, recommendation, or favoring by the United States Government or any agency thereof. The views and opinions of authors expressed herein do not necessarily state or reflect those of the United States Government or any agency thereof. 


\section{DISCLAIMER}

Portions of this document may be illegible in electronic image products. Images are produced from the best available original document. 


\section{COATING PROCESS}

The chemical reactions for selective $W$ deposition using chemical vapor deposition are given below:

$$
\begin{array}{r}
2 \mathrm{WF}_{6}+3 \mathrm{Si} \longrightarrow 2 \mathrm{~W}+3 \mathrm{SiF}_{4} \uparrow \\
W F_{6}+3 \mathrm{Si} \longrightarrow W+3 \mathrm{SiF}_{2} \uparrow
\end{array}
$$

When $W_{6}$ encounters heated silicon, a reaction occurs in which $\mathrm{SiF}_{4}$ or $\mathrm{SiF}_{2}$ gas is formed and $\mathrm{W}$ is deposited on the silicon surface. Depending on the reaction temperature one reaction or the other dominates $[10,13]$. Once a continuous film of $W$ is formed (after $-200 \AA$ on our structural polysilicon) the $\mathrm{WF}_{6}$ is shielded from the $\mathrm{Si}$ and the reaction slows or stops. This process is completely selective since the reaction does not occur on silicon dioxide or silicon nitride $[14,15]$.

The selective $W$ deposited on polysilicon surfaces is extremely conformal as shown in a SEM micrograph in Figure 2. After cleaving, the polysilicon has been etched using $\mathrm{HNO}_{3}: \mathrm{HF}$ to delineate the extremely thin $\mathrm{W}$ coating around the polysilicon. The $\mathrm{W}$ on the top surface is continuous even after this aggressive etch, demonstrating the absence of pin holes which would have been enhanced during delineation.

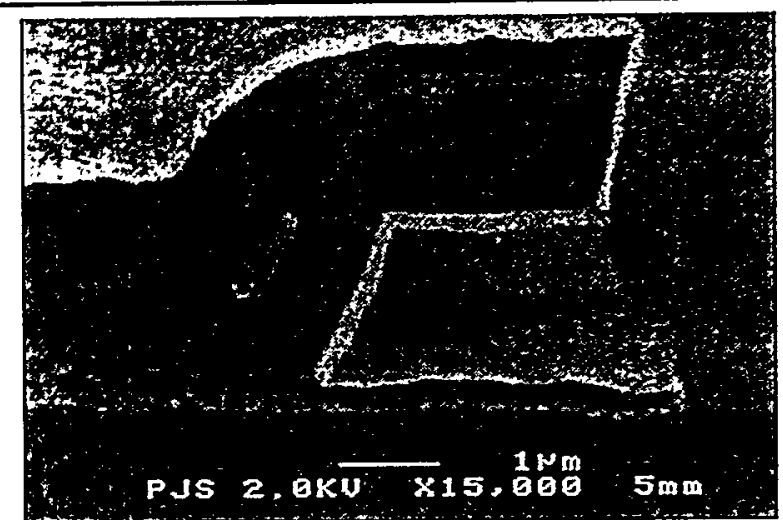

Figure 2. A scanning electron micrograph showing a thin $-100 \AA$ layer of silicon reduced $W$ conformal around all sides of a section of structural polysilicon. The silicon has been recessed using a $\mathrm{HF} / \mathrm{HNO}_{3}$ mixture in order to delineate the W.

During the displacement reduction reaction of $S i$ by $W_{6}$, the thickness of Si consumed is about twice the thickness of tungsten deposited. This inherent difference in the deposited film thickness and the reacted film thickness results in $\mathrm{W}$ depositing in very narrow spaces making this process desirable for MEMS devices. Figures 3a and $3 b$ show undercutting in initially adhered Si members. The SEM image shows the underside of a cantilever beam where $W$ has deposited. The structure was pulled using carbon-tape to image the underside. It appears that $\mathrm{W}$ has penetrated between layers of $\mathrm{Si}$, which were initially adhered. If the contact area is kept small this may be a way to address the as fabricated stiction problem. This is also important in that it is a mechanism for the coating of portions of parts that are unavoidably in local contact at the end of the drying process. Standard deposition processes either do not coat these contacting regions or can act to further glue them together.

\section{RELIABILITY}

\section{Microengines Functionality}

MEMS devices were selectively coated with $W$ using the selective silicon reduction process outlined above [15]. The

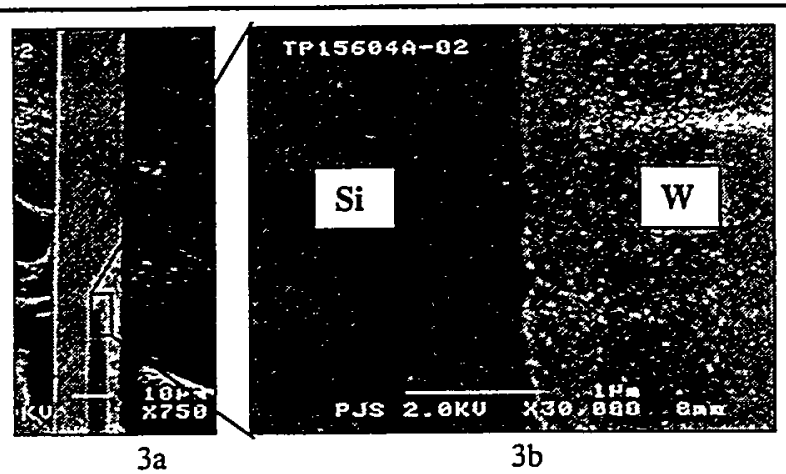

Figure 3 (a). Scanning electron micrograph of the backside of a cantilever beam showing $W$ encroachment underneath the beam, (b) higher magnification of the same region as in (a) showing $W$ and polysilicon regions.

microengine on the diagnostic module of the wafer was chosen for reliability and wear resistance assessment. It is of the same design as most of those tested in previous reliability experiments and is shown in Figure 4 [3-5, 16-18]. By applying the proper drive voltages, the linear displacement of the comb drives is transformed into circular motion. The $X$ and $Y$ linkage arms are connected to the gear via a pin joint. The gear rotates about a hub that is anchored to the substrate. The microengine has been the focus of much investigation for MEMS devices experiencing sliding friction [3-5].

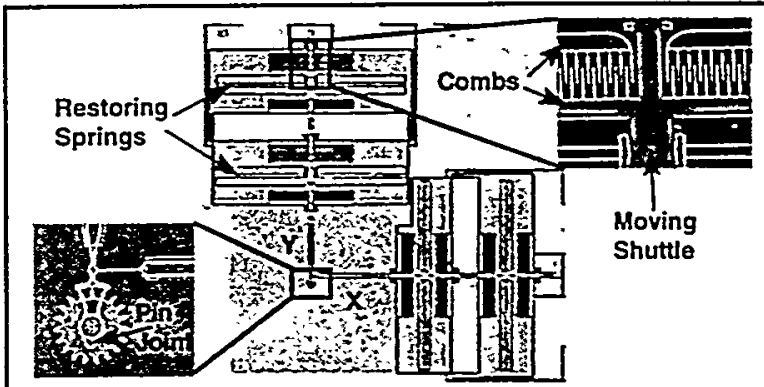

Figure 4. Sandia microengine with expanded views of the comb drive (top right) and the rotating gear (bottom left).

One of the many issues associated with assessing the reliability of microengines is the method used to operate them. Ideal equations (model-based), based on Newtonian physics, were derived to optimize the electrical signals [16]. In the typical optimization procedure, parameters were measured [17] which were then input into the equations. These equations are NOT simple sine waves, and it has been demonstrated that operation by square waves produced early failures [18].

To make a clean comparison to the polysilicon microengine, we decided to use the same drive parameters and frequency $(1720 \mathrm{~Hz})$ used in an earlier tests [3-5, 16-18]. All of the earlier tests were stressed with a large longitudinal force to accelerate the time to failure. The same was done with the tungsten-coated devices.

In our earlier tests without the coating, we observed a median time to failure of $4 \times 10^{5}$ accumulated cycles using a sample size of more than 20 microengines. This was performed in a controlled humidity environment of $39 \% \mathrm{RH}$. Using the same drive-signal parameters, but in ambient laboratory conditions (30-50\%RH), we observed a dramatic increase in the time to failure for $W$ coated parts. We saw no failures in 30 samples tested to 2 million cycles. Two microengines ran normally for $1,035,000,000$ and $379,000,000$ cycles respectively after which the test was stopped. One microengine was stressed using square waves and ran for 
$258,000,000$ cycles without failure. We would have expected this to run less than 100,000 cycles without the $W$ coating.

As shown in Figure 5, there is no apparent wear debris on the $\mathrm{W}$ coated devices. The polysilicon gear on the left failed after 1 million cycles with wear debris forming inside the hub and near the pin joint region. In comparison, on the right is a tungsten-coated microengine gear with no signs of wear debris after a billion cycles.

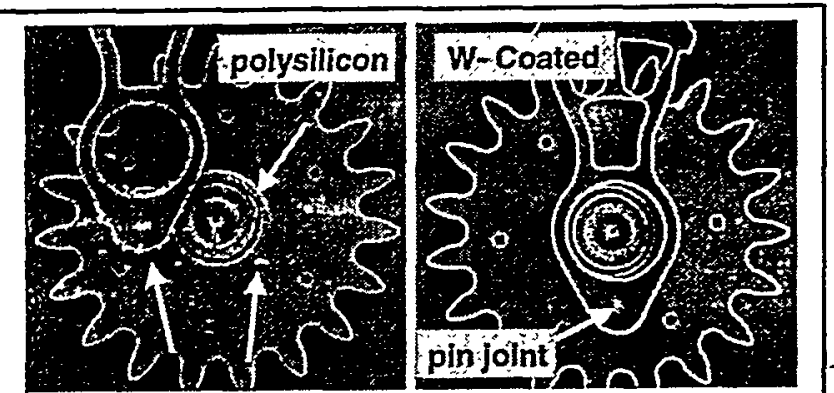

Figure 5. This SEM image shows the wear debris on the face of the polysilicon gear after 1 million cycles. Arrows indicate the location of wear debris. In contrast, the tungsten-coated gear has no indication of wear after 1 billion stress cycles. The gear diameter is 76 microns.

Further confirmation of excellent wear resistance is shown in Figure 6 by focused ion beam (FIB) cross sections of the pin joint region. The pin joint has a diameter of 3 microns. The uncoated polysilicon pin joint failed at 607,000 cycles and shows excessive wear with a significant narrowing of the diameter. Wear debris was present on all the rubbing surfaces. In contrast, the tungsten-coated pin joint shows no wear or wear debris anywhere near the rubbing surfaces.

Figure 7 shows the contacting surface below the revolving gear

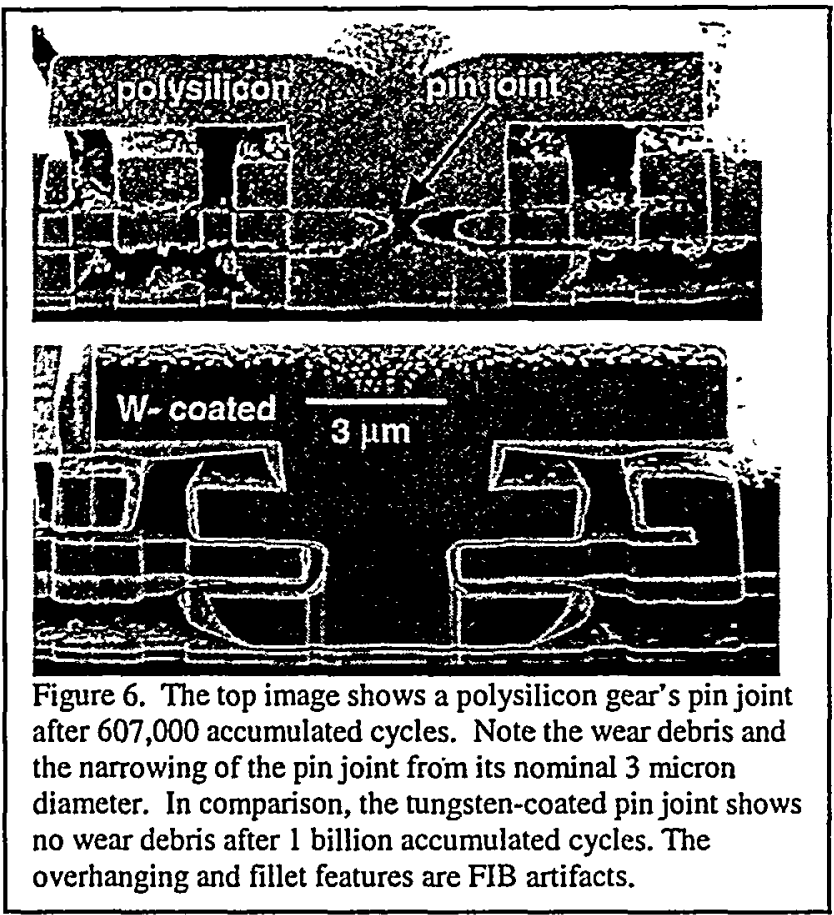

in a W-coated microengine. There are no wear tracks even after an accumulation of a billion cycles under accelerated test conditions. Normal operation is at much lower frequencies, therefore the parts last much longer than observed in the accelerated test conditions, making these parts very attractive for applications requiring long term use.

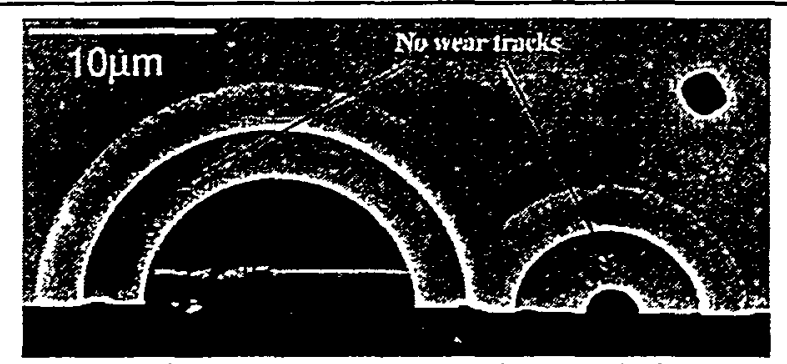

Figure 7. No wear tracks are observed around the hub and the pin joint in the case of a W coated microengine even after a billion cycles. The microengine components have been very delicately removed to image the contacting surfaces below the rotating gear. A Focussed Ion Beam technique was used to precisely cut the hub and pin joint area after which the scanning electron microscopy was used to examine the region for wear tracks.

\section{Mechanical Behavior}

Because it is relatively thin, we do not expect the $-15 \mathrm{~nm} \mathrm{~W}$ layer to strongly affect the basic mechanical properties ( $E$, Young's modulus, $D=E r^{3} / 12$ the bending stiffness, $R$ the radius of curvature and $\sigma_{R}$ the average residual stress through the thickness of the film) of the $2500 \mathrm{~nm}$ thick structural polysilicon/W composite. However, the mechanical properties and the density of $W$ are significantly different from polysilicon, and the $W$ is placed on the outside of the film where its impact on the effective bending stiffness is maximized. On the other hand, the overall film thickness is reduced about $30 \mathrm{~nm}$ when the $W$ is formed, which would counteract the increase in the bending. When taking these factors into account, the combined expected effect on $D$ is a $2 \%$ increase for the W-sandwich composite beam. It should also be considered that the $W$ layer is highly tensile ( $-1 \mathrm{GPa}$ ) because of the associated volume reduction when the $W$ formation takes place.

To assess the effect of the $W$ coating on the mechanical properties, two types of testing were carried out. For out-of-plane properties, we measured beam bending by interferometry under increasing voltages before pull-in [24], and for in-plane. properties we measured resonant frequency of comb resonators. The measurements were made on different wafers from the same lot. Because both of these types of measurements depend on the thickness or line width of the structure, wafer to wafer differences will also contribute to any differences found in the property measurements.

From the out-of-plane properties measurements, we first determined radii of curvature of $R=-0.5 \mathrm{~m}$ and $R=0.78 \mathrm{~m}$ for the uncoated and coated polysilicon respectively. In both cases, $R$ is large indicating that the average stress gradient through the thickness of the film is small. Next, $D$ for the coated film was found to be less than $10 \%$ greater than for the uncoated film. The effective modulus $E$ of the W-coated composite structure is within $5 \%$ of the uncoated structure. These numbers are in reasonable agreement with the expected effect calculated above. Finally, at less than $5 \mathrm{MPa}$, a small decrease in the average resjdual stress $\sigma_{R}$ was found for the coated relative to the $\mathrm{W}$-coated polysilicon. This is a small change, but the decrease rather than the increase of $\sigma_{R}$ is unexpected.

For the in-plane measurements, as measured on $10 \mathrm{~W}$-coated resonators, the average resonant frequency was $4.1 \mathrm{KHz}$, while typically it is $-4.3 \mathrm{KHz}$ for our standard release process. The resonant frequency $v_{R}=\sqrt{k / m}$ is a combined measurement of a number of both the spring constant $k$ as well as the mass $m$. The spring constant $k$ is directly related to the bending stiffness $D$, which 
we saw above is approximately the same for the coated compared to the uncoated material. However, the density of $\mathrm{W}$ is very high at 19 $\mathrm{g} / \mathrm{cm}^{3}$, while the density of $\mathrm{Si}$ is $2.3 \mathrm{~g} / \mathrm{cm}^{3}$. This would explain a decrease in $v_{R}$ of $4 \%$ (assuming a $15 \mathrm{~nm}$ thick W removing $30 \mathrm{~nm}$ of $\mathrm{Si}$ ). Therefore, the observed reduction in $v_{R}$ is perhaps mainly due to mass differences.

In summary, the basic mechanical properties of the W-coated polysilicon are dominated by the polysilicon structural material, and the effect of $\mathrm{W}$ is small. More investigation is required to understand the differences in $R$ and $\sigma_{\mathrm{R}}$ in detail. An effect on the fracture properties was more significant, as discussed in the next section.

\section{Tensile or Mechanical Strength}

During testing, the parts appeared to be more fragile, breaking relatively easily as compared to the uncoated parts. In order to quantify these qualitative observations we proceeded to test the strength of coated and uncoated parts. Miniature tensile samples have been tested to investigate the affect of tungsten coating on the strength of polysilicon. Each sample has a freely moving pivot and a pull-ring; the gage crossection is $1.8 \mu \mathrm{m}$ wide by $2.5 \mu \mathrm{m}$ thick and varies in length from 1.5 to $1000 \mu \mathrm{m}$. The pull-ring is engaged by a $35 \mu \mathrm{m}$ diameter flat tipped diamond using a nanoindenter. The normal force, lateral force and displacement are recorded. The normal force is maintained throughout the test to prevent the conical shaped diamond from being pushed upwards by the pull-ring engagement reaction. Once engaged, the tip continues to move laterally, which loads the thin polysilicon ligament in tension. Figure 8 shows two samples: the lower one has been tested to failure.

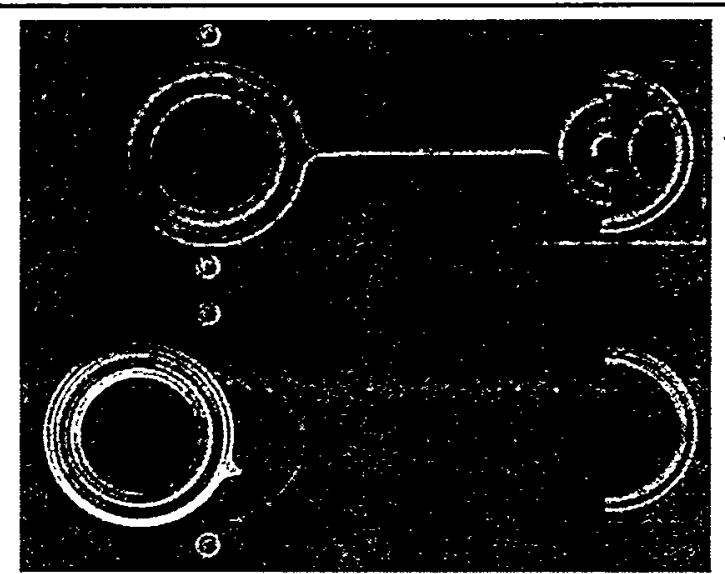

Figure 8. Two polysilicon tensile samples. The gage length for both samples is $90 \mu \mathrm{m}$. The lower sample has been tested; the energy released at fracture broke the pivot.

Ninety-eight conventionally released samples and fifty tungstencoated samples were tested in tension. The conventionally treated samples were subject to two release process as released and dried by supercritical carbon dioxide or released and coated with a PFTS self assembling monolayer. No difference in strength was found between these samples. Figure 9 shows the strength the two cases as released and tungsten coated tensile samples. Weibull analysis was performed on the strength data for the conventionally released samples [19]. A probability estimator in the form of $(j-0.5) / n$ was chosen [20]. The Weibull modulus, $\mathrm{m}$, was calculated to be 8.4 for the conventionally released samples and 5.3 for the $W$ coated samples. Figure 10 shows plots of the strength data for the Weibull analysis. The reduced strength does not effect the device performance and yields extended lifetime parts $[21,22]$.
Both strength and modulus for polysilicon must be evaluated in relation to fracture toughness and flaw size. The presence of defects can cause a drop in the modulus from that predicted from the elastic

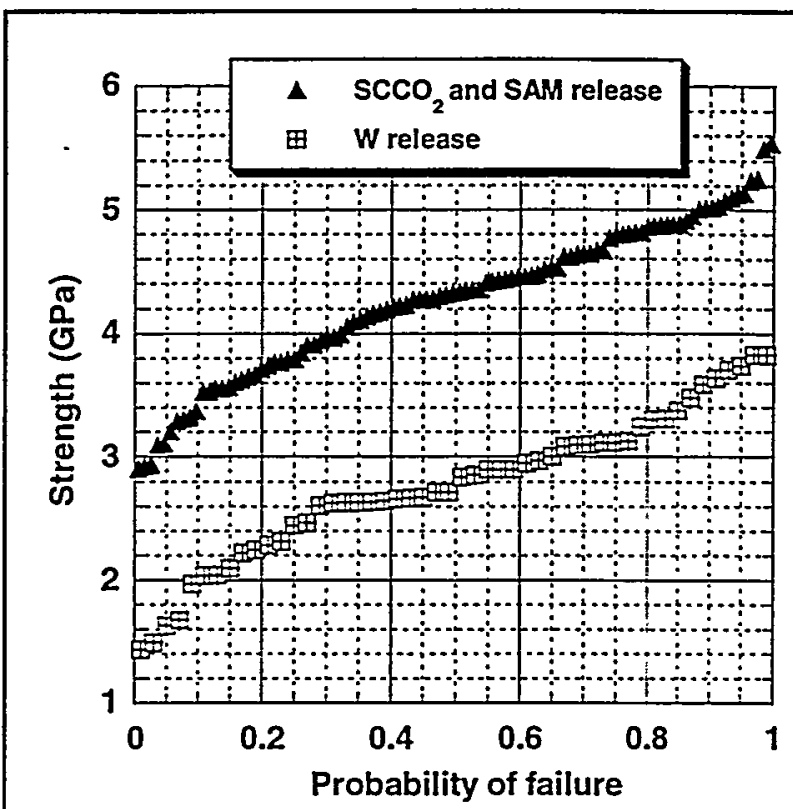

(b)

Figure 9. Strength of 98 conventionally released polysilicon samples and 50 tungsten coated samples Probability of Failure

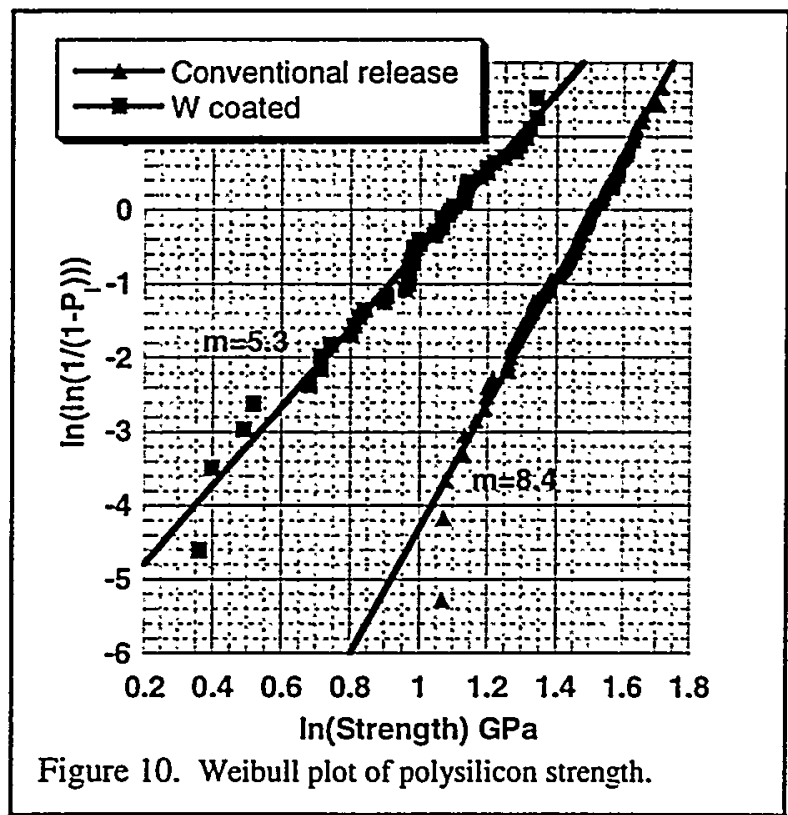

constants, however the volume fraction of such flaws has to be a recognizable percentage of the sample volume. Considering that this material has a fracture toughness on the order of 1-3 MPa $V_{m}$, flaws approximately $5-20 \mathrm{~nm}$ in size are responsible for initiating fracture $[21,23]$, which is a very small percentage of the cross section. Efforts to measure the fracture toughness of polysilicon produced at Sandia are underway. Figure 11 shows a classical brittle fracture surface from a tensile sample along with a TEM image of particle intrusions found at the W-polysilicon interface. The size of these flaws is consistent with the equations in the literature. Even though 
the grain size is approaching the size of critical features, the critical flaw size is much smaller than either of these dimensions, and it appears that there is no issue in scaling the fracture analysis.

Sidewall Friction Device

The sidewall friction device consists of two orthogonal

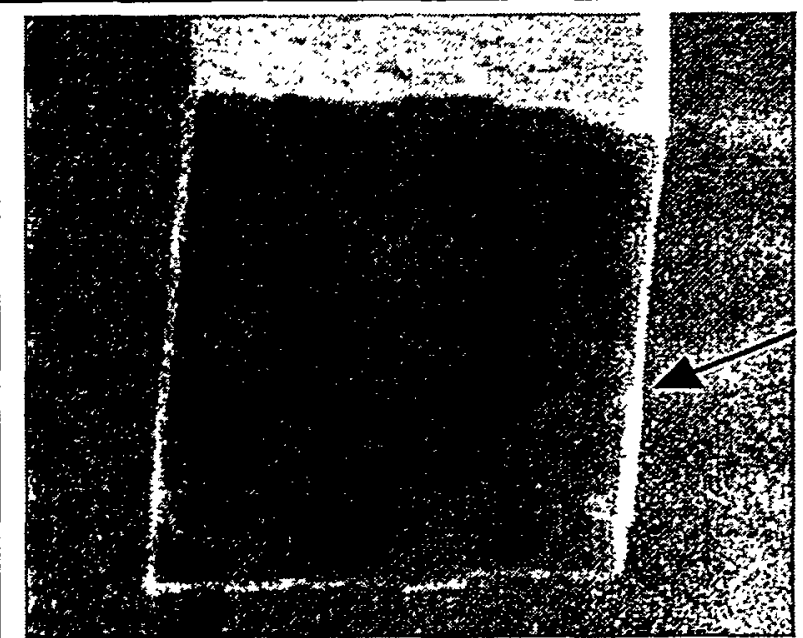

(a)

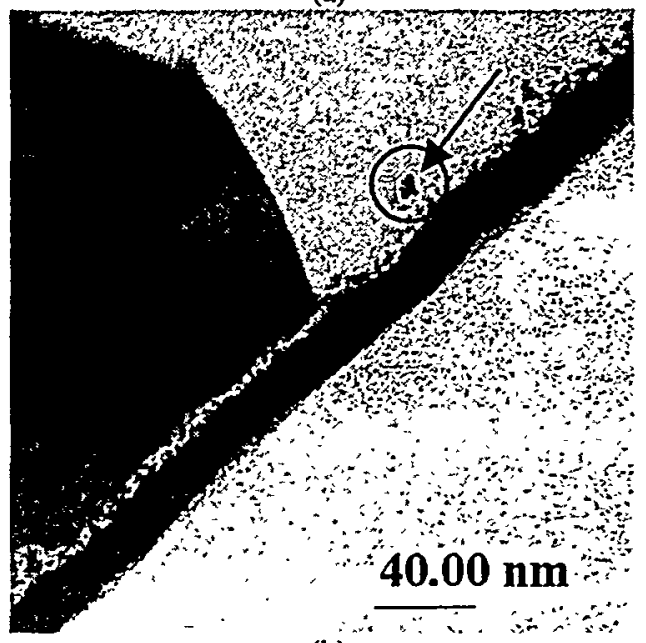

(b)

Figure 11. W coated polysilicon samples (a) fracture surface with crack initiation marked (b) TEM cross section showing particle intrusion at W-polysilicon interface.

electrostatic comb actuators connected to a movable beam. The beam is suspended above the substrate by the folded spring suspensions on the comb actuators. A post is formed by etching through sacrificial oxide layers so that a polysilicon deposition forms a structure, which is anchored to the substrate and has a cylindrical geometry facing the beam. The device is actuated by using a DC voltage on the loading comb to bring the beam into contact with the post, and then applying a waveform to the oscillation comb to slide the beam against the post.

The friction coefficient exhibited by the tungsten coated surfaces in laboratory air, measured using the sidewall friction tester, and is shown in Figure 12. The friction coefficient is initially near 0.07 , and decreases to about 0.05 after several thousand cycles of operation. The small decrease in friction after the start of sliding is consistent with a minor amount of run-in, where the highest surface asperities are removed and improved conformality of the sliding surfaces is established. .. The kinetic friction coefficient value is comparable to that observed with fluorocarbon silane films on polycrystalline silicon [25]. This value is lower than would be expected from self-mated tungsten surfaces in environments containing water vapor, from macroscopic measurements [26]. Even self-mated tungsten carbide surfaces, which would represent contact between covalently bound surface layers analogous to the natural oxide surfaces, would not be expected to exhibit a friction coefficient this low. Since the friction coefficient is much lower than that observed in macroscopic sliding experiments with tungsten, we believe that the friction behavior of the tungsten coated surface is governed by the presence of another surface film. This film may be a residual layer from the tungsten deposition process itself that effectively prevents metallic contact of the tungsten surfaces. Compositional analysis of wom surfaces is underway to test this hypothesis. In fact, the friction coefficient observed for the tungsten coated surface in micromachine contacts is in the range of values observed with metal dichalcogenide solid lubricant films such as $\mathrm{MoS}_{2}, \mathrm{WS}_{2}$ or $\mathrm{WSe}_{2}$ [27].

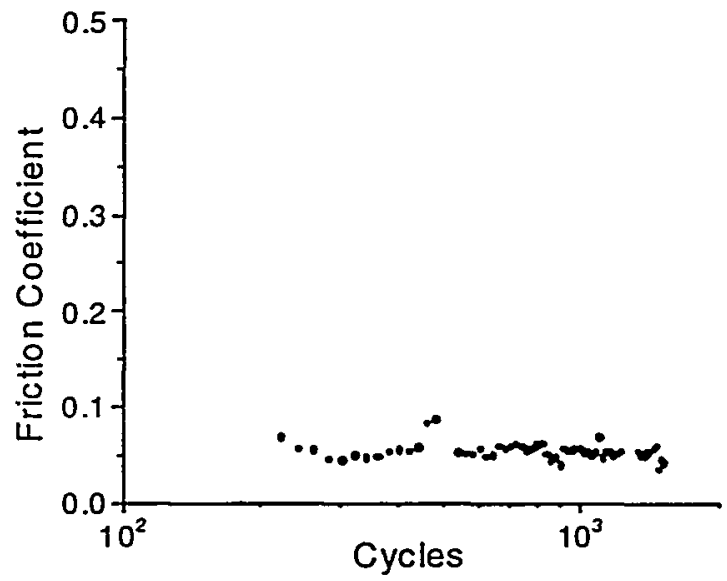

Figure 12. Friction coefficient as a function of the number of sliding cycles (one cycle $=$ a complete forward and reverse oscillation) for a tungsten coated sidewall friction tester operated in laboratory air.

\section{CONCLUSIONS}

Selective tungsten coating using chemical vapor deposition has been used to deposit a thin, uniform, conformal coating to improve wear resistance. This $\mathrm{W}$ coating shows dramatic improvements in wear characteristics. Microengines coated with selective $W$ show longer lifetimes than polysilicon microengines. The mean time to failure observed in polysilicon microengines was $4 \times 10^{5}$ using 20 microengines. In comparison, in the tungsten coated microengines no failure was observed in 30 microengines tested to 2 million cycles. The tungsten coating changes the mechanical behavior of the polysilicon structure, while satisfying the MEMS devices requirements and not influencing the device performance. Hence, this coating is well suited for MEMS applications.

\section{ACKNOWLEDGEMENTS}

The United States Department of Energy under contract DEAC04-94AL85000 supported this work. Sandia is a multiprogram laboratory operated by Sandia Corporation, a Lockheed Martin Company, for the United States Department of Energy. The authors 
acknowledge the staff in MDL for their efforts and Pat Shea for all the SEM work and Alex Pimental for the FIB cuts.

\section{REFERENCES .}

1. R. T. Howe and R. S. Muller, J. Electrochem Soc: Solid State Science \& Technology, 103(6) p. 1420 (1983).

2. E. J. Garcia and J. J. Sniegowski, Sensors and Actuators A, 48, p. 203 (1995).

3. S. L. Miller, J. J. Sniegowski, G. LaVigne, and P. J. McWhorter in Proceedings of SPIE Smart Electronics and MEMS 2722, p. 197 (1996).

4. Danelle M. Tanner, W. M. Miller, W. P. Eaton, L. W. Irwin, K. A. Peterson, M. T. Dugger, D. C. Senft, N. F. Smith, P. Tangyunyong, and S. L. Miller in 1998 IEEE International Reliability Physics Proceedings, p. 26 (1998).

5. Danelle M. Tanner, Jeremy A. Walraven, Lloyd W. Irwin, Michael T. Dugger, Norman F. Smith, William M. Miller, and Samuel L. Miller in Proc. Of IEEE Intemational Reliability Physics Symposium, p. 189 (1999).

6. K. Deng, R. J. Collins, M. Mehrengany and C. N. Sukenik, J. Elctrochem. Soc., 142(4), p. 1278 (1995).

7. U. Srinivasan, M. R. Houston, R. T. Howe and R. Maboudian, J. Micromech. Sys., 7(2), p. 252 (1998).

8. D. R. Bradbury, J. E. Tumer, K. Nauka and K. Y. Chiu, IEDM, p. 273, (1991).

9. M. Sekine, Y. Kakuhara, K. Yamazaki and Y. Murao, MRS Advanced Metallization ULSI Applications, p. 255. (1991).

10. M. L. Yu, B. N. Eldridge, and R. V. Joshi, in Deposition and Growth: Limits for Microelectronics, edited by G. W. Rubloff (AIP Conf. Proc. 167, New York 1988), p. 202.

11. E. K. Broadbent and C. L. Ramiller, J Elctrochem. Soc.: SolidState Science and Techonolgy, 131(6), p. 1427 (1984).

12. M. L Green and R. A. Levy, J Elctrochem. Soc.: Solid-State Science and Techonolgy, 132(5), p. 1243 (1985).

13. M. L. Yu, B. N. Eldridge, and R. V. Joshi. in Tungsten and Other Refractory Metals for VLSI Applications III, edited by V. A. Wells (MRS Proc. Pittsburgh, PA), 1988, p. 75.

14. A. Kepten, A. Reisman, M. Ray, P. L. Smith, D. Temple, and F. Tapp, J. Electrochem. Soc, 139(8), p. 2331 (1992).

15. S. S. Mani, J. G Fleming, and J. J. Sniegowski in Proceedings of SPIE, Micromachining and Microfabrication Process Technology' $V$, 3874, p.150 (1999).

16. S. L. Miller, J. J. Sniegowski, G. LaVigne, and P. J. McWhorter in Proceedings of SPIE Micromachined Devices and Components II, 2882, p. 182 (1996).

17. Norman F. Smith, William P. Eaton, Danelle M. Tanner, and James J. Allen in SPIE Proceedings, 3880, p. 156 (1999).

18. S. L. Miller, M. S. Rodgers, G. LaVignie, J. J. Sniegowski, P. Clews, D. M. Tanner, K. A. Peterson in Proc. Of IEEE International Reliability Physics Symposium, p. 17 (1998).

19. W. Weibull, in Proceedings Royal Swedish Institute for Engineering Research, $(151,1939)$ pp. 1-45.

20. Sullivan, J.D. and P.H. Lauzon, J. Materials Science Letters, 5, pp. 1245-1247 (1986).

21. S. S. Mani, J.G. Fleming, J.J. Sniegowski, M.P. de Boer, L. W. Irwin, J. A. Walraven, D. M. Tanner, D. A. LaVan in Materials Science of Microelectromechanical Systems (MEMS) II. (MRS Proc. 1999). submitted.

22. D. A. LaVan, T.E. Buchheit, and M. Nowell in Materials Science of Microelectromechanical Systems (MEMS) Devices II, (MRS Proc. 1999), submitted.

23. T. L. Anderson, Fracture Mechanics, 2nd ed., CRC Press, Boca Raton, FL 1995.

24. B. D. Jensen, M. P. de Boer and S. L. Miller, MSM 99, San Juan, Puerto Rico, 1999, pp. 206-209.
25. D. M. Tanner, J. A. Walraven, L. W. Irwin, M. T. Dugger, N. F. Smith, W. M. Miller, and S. L. Miller, Proc. of IEEE International Reliability Physics Symposium, 1999, p. 189.

26. E. Rabinowicz, ASLE Trans., 14 (1971) p. 198.

27. J.-Ph. Nabot, A. Aubert, R. Gillet, and Ph. Renaux, Surface and Coatings Technology $43 / 44$ (1990) p. 629. 